\title{
Genetic polymorphisms of non-coding RNAs associated with increased head and neck cancer susceptibility: a systematic review and meta-analysis
}

\author{
Weiyi Pan ${ }^{1, *}$, Chenzhou Wu ${ }^{1,2,}{ }^{*}$, Zhifei Su${ }^{1}$, Zexi Duan ${ }^{1}$, Longjiang Li $^{1,2}$, Fanglin Mi $^{3}$ \\ and Chunjie $\mathbf{L i}^{1,2}$ \\ ${ }^{1}$ State Key Laboratory of Oral Diseases, West China Hospital of Stomatology, Sichuan University, Chengdu, China \\ ${ }^{2}$ Department of Head and Neck Oncology, West China Hospital of Stomatology, Sichuan University, Chengdu, China \\ ${ }^{3}$ Department of Stomatology, Affiliated Hospital of North Sichuan Medical College, Sichuan, China \\ *Co-First authors
}

Correspondence to: Fanglin Mi, email: 1498092988@qq.com

Chunjie Li, email: lichunjie@scu.edu.cn

Keywords: genetic polymorphisms, non-coding RNAs, head and neck cancer, cancer susceptibility, systematic review

Received: May 01, 2017 Accepted: July 26, $2017 \quad$ Published: August 09, 2017

Copyright: Pan et al. This is an open-access article distributed under the terms of the Creative Commons Attribution License 3.0 (CC BY

$3.0)$, which permits unrestricted use, distribution, and reproduction in any medium, provided the original author and source are credited.

\section{ABSTRACT}

Genetic polymorphisms, including single nucleotide polymorphisms (SNP) and nucleotide repeat expansions, can occur in regions that transcribe non-coding RNAs (ncRNA), such as, but not limited to, micro RNA and long non-coding RNA. An association between genetic polymorphisms of ncRNA and increasing head and neck cancer (HNC) risk has been identified by several studies. Therefore, the aim of this systematic review is to consolidate existing findings to clarify this association. Four electronic databases, such as MEDLINE, EMBASE, Chinese BioMedical Literature Database, and China National Knowledge Infrastructure, were utilised. Inclusion of studies and data extraction were accomplished in duplicate. A total of 42 eligible studies were included, involving 28,527 cases and 37,151 controls. Meta-analysis, sensitivity analysis and publication bias detection were performed. Among the eligible studies, 102 SNPs were investigated, and 21 of them were considered eligible for meta-analysis. Our analysis revealed that HOTAIR rs920778, uc003opf. 1 rs11752942, and miR-196a2 rs11614913 were related to HNC susceptibility, while let-7 rs10877887, miR-124-1rs531564, and miR-608 rs4919510 were considered as protective factors. In conclusion, our results showed the extreme importance of an up-to-date comprehensive meta-analysis encompassing the most recent findings to obtain a relevant and reliable framework to understand the relationship between ncRNA SNPs and HNC susceptibility.

\section{INTRODUCTION}

Head and neck cancer (HNC) is a broad term encompassing epithelial malignancies located in the oral cavity, pharynx, larynx, cervical oesophagus, paranasal sinuses, nasal cavity, salivary glands and thyroid gland [1-3]. The anatomical sites affected by HNC are of great importance in several functions such as speech, smell, swallowing and chewing. Thus, HNC and tumour removal can greatly impact quality of life $[1,3]$. According to the GLOBOCAN 2008 study, HNC is the sixth most common type of cancer worldwide, accounting for an estimated number of 650,000 new cancer cases and 350,000 cancer deaths every year [3, 4]. It is worth noting that only a third of HNC patients present at the early stage of disease, but after appropriate treatments, the cure rate can reach up to $90 \%$ in patients with stage I disease and about $70 \%$ in patients with stage II disease [3]. Thus, HNC patients can benefit from early diagnosis and treatment. Identification of the risk factors contributing to HNC susceptibility may be helpful for early management. Oral tobacco use (smoking and betel quid chewing), alcohol consumption, 
viral infections (Epstein-Barr virus and human papilloma virus), dental hygiene, and dietary factors are proven risk factors for $\mathrm{HNC}$ [5-7]. In addition to the above environmental factors, a role of genetic factors in HNC cancer development has also been confirmed [8]. Recently, genetic polymorphisms in genes encoding non-coding RNAs (ncRNAs) have been linked with HNC risk.

Pervasive transcription of human genomes has been demonstrated with the development of whole genome technologies. Interestingly, only $2 \%$ of transcripts encode proteins, while most transcripts are ncRNAs [8-11]. ncRNA can be functionally divided into the following three subgroups: 1) 'housekeeping' ncRNAs, including ribosomal RNA, transfer RNA, small nuclear RNA and small nucleolus RNA, 2) regulatory ncRNAs, including micro RNAs (miRNAs), long non-coding RNAs (lncRNAs), small interfering RNAs, and PIWI-interacting RNAs, and 3) several other poorly characterized types of ncRNAs [11, 12]. The most important cancer-related ncRNAs include the broadly investigated miRNAs, as well as the recently recognized lncRNAs [12].

MiRNAs are small ncRNAs of 21-23 nucleotides, which use partial base-pairing to recognize target messenger RNAs, thus repressing their expression [13]. Hence, miRNAs play an important role in several fields including angiogenesis, epithelial-mesenchymal transition and drug resistance by targeting various oncogenes and tumour suppressors in cancer cells $[13,14]$. IncRNAs are defined as transcripts longer than 200 nucleotides with little or no open reading frames [15]. The regulatory mechanisms of lncRNAs are much more complicated than that of miRNAs, and include chromatin reprogramming, post-transcriptional regulation, protein localization, RNA interference $[16,17]$. Although the exact biological role of most lncRNAs remain unclear, there is increasing evidence to suggest that lncRNAs are associated with carcinogenesis and act as an important component of tumour biology $[17,18]$.

Despite physical differences, human populations are $99 \%$ genetically identical, which means that human diversity, including cancer susceptibility, results from the remaining $1 \%$ of genetic polymorphisms [19-21]. Small- and large-scale genetic polymorphisms, including single nucleotide polymorphisms (SNPs), nucleotide expansions, copy-number alterations, and chromosomal translocations, can occur in non-coding regions of the genome [22]. Most of these genetic polymorphisms are due to SNPs caused by single nucleotide mutations that occur on average approximately once in 100 to 300 base pairs in the human genome [20]. Since Abelson et al. in 2005 firstly demonstrated the association between SNPs in miRNA-related genes and Tourette's syndrome [23], SNPs in genes encoding ncRNAs have been widely investigated, especially in the field of cancer susceptibility [24-27]. To date, accumulating evidence has revealed a link between ncRNA polymorphisms and HNC susceptibility. To date, there is some evidence showing a link between ncRNA polymorphisms and HNC susceptibility. However, the results of epidemiological studies have been inconsistent. Therefore, the aim of this systematic review was to consolidate existing findings to clarify this association.

\section{RESULTS}

\section{Study identification}

The process of study identification was showed in Supplementary Figure 1.

After the removal of duplicates, 193 records were identified through electronic database searching and manual searching. One hundred and thirty-one records were excluded after the screening of the abstract, while the full texts of the remaining 62 records were analysed to confirm their eligibility. Among these 62, 20 were excluded, such as three studies in which primary head and neck cancer was actually not diagnosed, seven studies that did not investigate ncRNA polymorphisms, six studies that did not analyse the association between genetic polymorphism and cancer risk, and four studies that did not report sufficient data for statistical analysis. Finally, 42 studies [28-69] were considered eligible for this metaanalysis and included.

\section{Study characteristics}

Among the 42 included studies, six studies $[28,43,46,58,62,64]$ contained multiple cohorts, thus were considered as independent studies. For this reason, a total of 50 comparisons were included in this systematic review, which investigated 102 different polymorphisms in a large number of cases and controls amounting 28,527 and 37,151, respectively. Regarding ncRNAs genetic polymorphisms, only studies that investigated lncRNAs and miRNAs SNPs were found. The ethnic background of the participants included Asian [30, 32, 33, 35-38, 42, 44-51, 53-59, 61-69], Black [43], Caucasian [28, 31, 34, 39-41, 52, 60], and mixed [29, 43]. Several cancer types were investigated, such as oesophageal cancer [30, 32, $42-44,46,47,49,53,55,57,58,60,63,65,68]$, head and neck squamous cell carcinoma (HNSCC) [29, 31, 35, 40], nasopharyngeal carcinoma (NPC) [36, 38, 48, 50, 64], oral squamous cell carcinoma (OSCC) $[33,37,41,51,52$, $54,59,62]$, and thyroid carcinoma $[28,34,39,45,56,61$, $66,67,69]$. It is important to mention that four studies $[29,41,46,60]$ did not completely report the distribution of three genotypes, although, these data were extracted and analysed as well. All included studies were case control studies. The remaining characteristics of the included studies were listed in Supplementary Table 1.

After the screening of the full text and data extraction, 21 out of 102 SNPs were considered eligible for meta-analysis. Among them, two SNPs were located into lncRNAs, and the rest were located into miRNAs. 
The control group of nine cohorts from six studies $[33,43,44,59,65,66]$ were not in agreement with HWE $(P>0.05)$. Except all the three cohorts of miR-2191 rs213210 and two of the four cohorts of miR-26a-1: rs7372209, the rest cohorts were of different SNPs (listed in detail in Supplementary Table 1). The detailed information of these SNPs was listed in Table 1, while the SNPs that were not eligible for meta-analysis were listed in Supplementary Table 2.

The result of methodological quality assessment by Newcastle-Ottawa quality assessment scale (NOS) of included studies was listed in Supplementary Table 1. Among the 50 cohorts from 42 included studies, two $[34,54]$ were considered as high risk of bias, $19[28,33$, $35,37-39,43,48,49,52,56,60,61,63,67,69]$ were considered as medium risk of bias, and the rest 29 were considered as low risk of bias.

\section{Meta-analysis results}

Meta-analysis results are listed in Supplementary Table 4. IncRNA SNPs, HOTAIR rs920778 (C/T) and uc003opf.1 rs11752942 (A/G) were considered eligible for

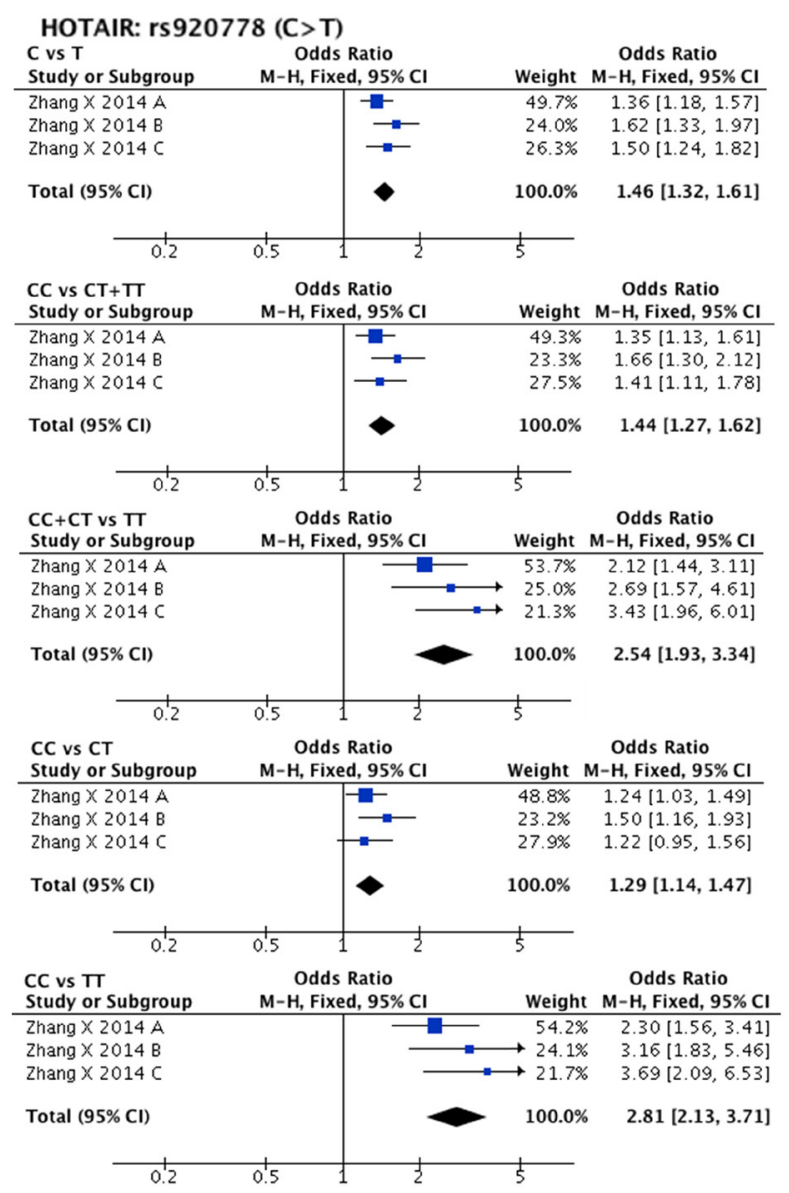

meta-analysis. For HOTAIR rs920778, three comparisons were found in a single study including 2098 cases and 2150 controls, and for uc003opf.1 rs11752942, two comparisons were found also in a single study including 1493 cases and 1553 controls, respectively [46, 58]. A significant association was found in all genetic models between oesophageal squamous cell carcinoma (abbreviated to ESCC to differentiate it from oral squamous cell carcinoma) susceptibility and both HOTAIR rs920778 (C allele vs. T allele: $\mathrm{OR}=1.46,95 \% \mathrm{CI}=1.32-1.61, \mathrm{P}-\mathrm{H}=0.37$; $\mathrm{CC}$ vs. $\mathrm{CT}+\mathrm{TT}$ : $\mathrm{OR}=1.44,95 \% \mathrm{CI}=1.27-1.62, \mathrm{P}-\mathrm{H}=0.40$; $\mathrm{CC}+\mathrm{CT}$ vs. TT:OR $=2.54,95 \% \mathrm{CI}=1.93-3.34, \mathrm{P}-\mathrm{H}=$ 0.37 ; CC vs. $\mathrm{CT}: \mathrm{OR}=1.29,95 \% \mathrm{CI}=1.14-1.47, \mathrm{P}-\mathrm{H}=$ 0.43 ; $\mathrm{CC}$ vs. TT:OR $=2.81,95 \% \mathrm{CI}=2.13-3.71, \mathrm{P}-\mathrm{H}=$ 0.36 ) and uc003opf.1 rs11752942 (A allele vs. G allele: $\mathrm{OR}=0.75,95 \% \mathrm{CI}=0.68-0.83, \mathrm{P}-\mathrm{H}=0.57$; AA vs. $\mathrm{AG}+$ GG: $\mathrm{OR}=0.72,95 \% \mathrm{CI}=0.62-0.83, \mathrm{P}-\mathrm{H}=0.50 ; \mathrm{AA}+\mathrm{AG}$ vs. $\mathrm{GG}$ : $\mathrm{OR}=0.62,95 \% \mathrm{CI}=0.50-0.78, \mathrm{P}-\mathrm{H}=0.91$; $\mathrm{AA}$ vs. $\mathrm{AG}: \mathrm{OR}=0.77,95 \% \mathrm{CI}=0.66-0.89, \mathrm{P}-\mathrm{H}=0.53$; $\mathrm{AA}$ vs. $\mathrm{GG}: \mathrm{OR}=0.54,95 \% \mathrm{CI}=0.43-0.69, \mathrm{P}-\mathrm{H}=0.74)$. The forest plot of the comparisons above is shown in Figure 1. We did not perform subgroup analysis since no significant clinical and statistical heterogeneity were found.

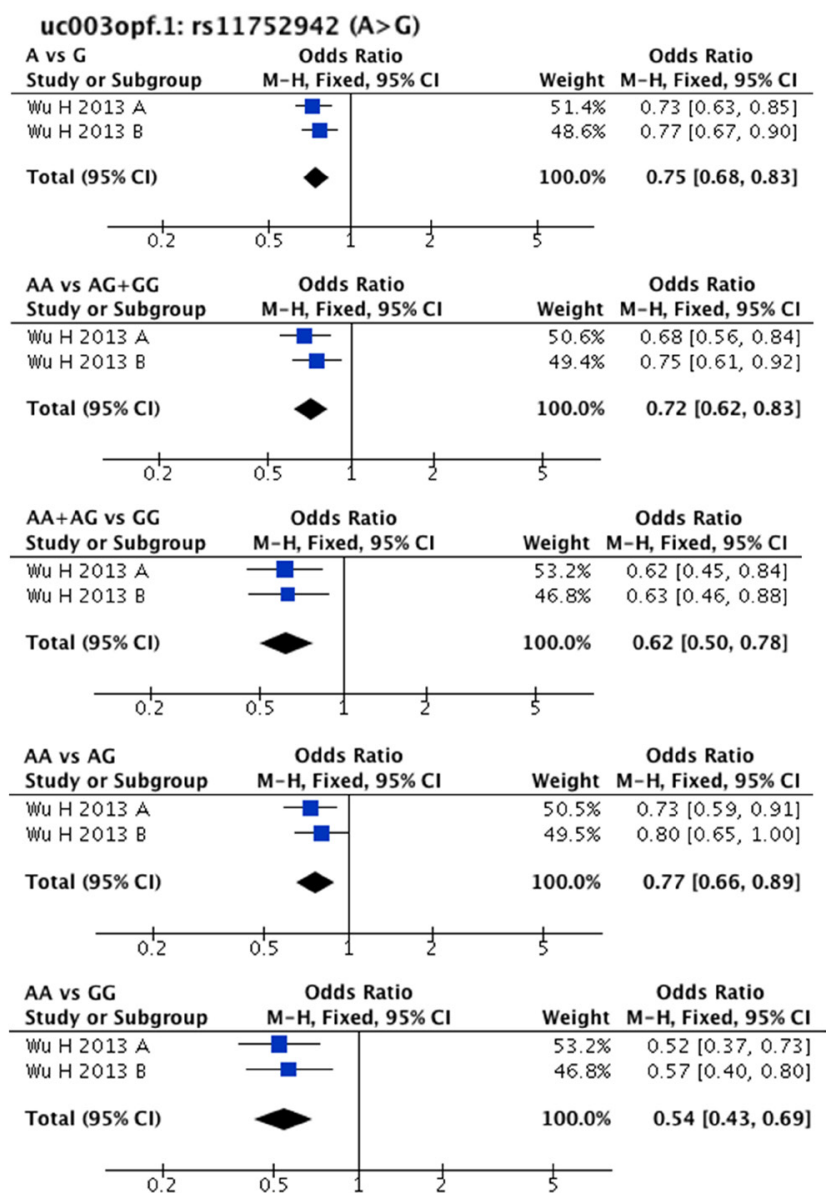

Figure 1: Forest plots of effect estimates for two IncRNAs HOTAIR rs920778 and uc003opf.1 rs11752942. Five forest plots of each lncRNA are corresponded to five genetic models (allele contrast, dominant model, recessive model, and two co-dominant models). 
Table 1: Characteristics of SNPs that eligible for meta-analysis

\begin{tabular}{|c|c|c|c|c|c|c|c|}
\hline ncRNA & SNP & $\begin{array}{l}\text { Ancestral } \\
\text { Allele }\end{array}$ & $\begin{array}{c}\text { SNP } \\
\text { Alleles }\end{array}$ & Ethnic & Cancer type & $\begin{array}{l}\text { Number of } \\
\text { Studies * }\end{array}$ & References \\
\hline \multicolumn{8}{|l|}{ IncRNAs } \\
\hline HOTAIR & rs920778 & $\mathrm{C}$ & $\mathrm{C} / \mathrm{T}$ & Asian & ESCC & 3 & {$[58]$} \\
\hline $\begin{array}{l}\text { uc003opf.1 } \\
\text { miRNAs }\end{array}$ & rs11752942 & A & $\mathrm{A} / \mathrm{G}$ & Asian & ESCC & 2 & {$[46]$} \\
\hline let-7 & rs 10877887 & $\mathrm{~T}$ & $\mathrm{~T} / \mathrm{C}$ & Asian & OSCC,PTC & 2 & {$[59,66]$} \\
\hline let-7 & rs13293512 & $\mathrm{T}$ & $\mathrm{T} / \mathrm{C}$ & Asian & OSCC,PTC & 2 & {$[59,66]$} \\
\hline miR-26a-1 & rs7372209 & $\mathrm{C}$ & $\mathrm{T} / \mathrm{C}$ & $\begin{array}{l}\text { Asian, Black, } \\
\text { Mixed }\end{array}$ & ESCC & 4 & {$[42-44]$} \\
\hline $\operatorname{miR}-27 a$ & rs895819 & $\mathrm{T}$ & $\mathrm{T} / \mathrm{C}$ & Asian & ESCC & 2 & {$[44,57]$} \\
\hline $\mathrm{miR}-34 \mathrm{~b} / \mathrm{c}$ & rs4938723 & $\mathrm{T}$ & $\mathrm{T} / \mathrm{C}$ & Asian & $\begin{array}{c}\text { ESCC, NPC, } \\
\text { PTC }\end{array}$ & 4 & {$[36,47,57,61]$} \\
\hline miR-124-1 & rs531564 & $\mathrm{C}$ & $\mathrm{G} / \mathrm{C}$ & Asian & ESCC & 2 & {$[47,57]$} \\
\hline miR-146a & rs2910164 & G & $\mathrm{C} / \mathrm{G}$ & $\begin{array}{l}\text { Asian, } \\
\text { Caucasian }\end{array}$ & $\begin{array}{c}\text { ESCC, } \\
\text { HNSCC, } \\
\text { LSCC, NPC, } \\
\text { OSCC, TC }\end{array}$ & 20 & $\begin{array}{l}{[28,30,31,33,34,38-41,42,} \\
44,45,48,51,52,53,67,69]\end{array}$ \\
\hline miR-149 & rs2292832 & $\mathrm{C}$ & $\mathrm{T} / \mathrm{C}$ & $\begin{array}{l}\text { Asian, } \\
\text { Caucasian }\end{array}$ & $\begin{array}{l}\text { ESCC, OSCC, } \\
\text { PTC }\end{array}$ & 5 & {$[31,33,35,41,56]$} \\
\hline miR-196a2 & rs11614913 & $\mathrm{C}$ & $\mathrm{C} / \mathrm{T}$ & $\begin{array}{l}\text { Asian, } \\
\text { Caucasian, } \\
\text { Mixed }\end{array}$ & $\begin{array}{c}\text { ESCC, } \\
\text { HNSCC, NPC, } \\
\text { OSCC, PTC }\end{array}$ & 13 & $\begin{array}{c}{[29,31-33,37,41,42,44,50} \\
53-55,67]\end{array}$ \\
\hline miR-218-2 & rs 11134527 & G & $\mathrm{G} / \mathrm{A}$ & Asian & ESCC & 2 & {$[49,57]$} \\
\hline miR-219-1 & rs213210 & $\mathrm{T}$ & $\mathrm{T} / \mathrm{C}$ & $\begin{array}{l}\text { Asian, Black, } \\
\text { Mixed }\end{array}$ & ESCC & 3 & {$[43,65]$} \\
\hline $\mathrm{miR}-423$ & rs6505162 & $\mathrm{C}$ & $\mathrm{A} / \mathrm{C}$ & $\begin{array}{l}\text { Asian, Black, } \\
\text { Mixed }\end{array}$ & ESCC & 4 & {$[42,43,47]$} \\
\hline miR-449b & rs10061133 & A & $\mathrm{A} / \mathrm{G}$ & Asian & ESCC, PTC & 2 & {$[67,68]$} \\
\hline miR-499a & rs3746444 & $\mathrm{T}$ & $\mathrm{T} / \mathrm{C}$ & $\begin{array}{l}\text { Asian, } \\
\text { Caucasian }\end{array}$ & $\begin{array}{c}\text { ESCC, } \\
\text { HNSCC, NPC, } \\
\text { OSCC, PTC }\end{array}$ & 9 & $\begin{array}{c}{[31,33,41,42,44,62} \\
64,67]\end{array}$ \\
\hline miR-608 & rs4919510 & G & $\mathrm{C} / \mathrm{G}$ & Asian & $\begin{array}{l}\text { ESCC, NPC, } \\
\text { PTC }\end{array}$ & 4 & {$[64,67,68]$} \\
\hline miR-627 & rs2620381 & $\mathrm{A}$ & $\mathrm{A} / \mathrm{C}$ & Asian & ESCC, PTC & 2 & {$[67,68]$} \\
\hline miR-646 & rs6513497 & $\mathrm{T}$ & $\mathrm{T} / \mathrm{G}$ & Asian & ESCC, PTC & 2 & {$[67,68]$} \\
\hline miR-3152 & rs13299349 & G & $\mathrm{G} / \mathrm{A}$ & Asian & NPC, PTC & 2 & {$[64,67]$} \\
\hline miR-4293 & rs12220909 & G & $\mathrm{G} / \mathrm{C}$ & Asian & $\begin{array}{c}\text { ESCC, NPC, } \\
\text { PTC }\end{array}$ & 3 & {$[64,67,68]$} \\
\hline
\end{tabular}

*: the cohorts would be considered as different studies if more than one cohort were reported separately in one single study. ncRNA: noncoding RNAs; SNPs: single nucleotide polymorphisms; lncRNAs: long noncoding RNAs; miRNAs: micro RNAs; ESCC: esophageal squamous cell carcinoma; HNSCC: head and neck squamous cell carcinoma; NPC: nasopharyngeal carcinoma; OSCC: oral squamous cell carcinoma; PTC: papillary thyroid carcinoma; LSCC: laryngeal squamous cell carcinoma; TC: thyroid carcinoma.

A total of 19 SNPs found into miRNAs gene loci were included into meta-analysis. The overall pooled result showed a significant association between miRNA SNP and increased HNC risk only in 1 SNP, such as miR-196a2 rs11614913 (C/T), in co-dominant model (CC vs. CT: $\mathrm{OR}=1.12,95 \% \mathrm{CI}=1.03-1.22$, $\mathrm{P}-\mathrm{H}=0.07)$, which was supported by 13 comparisons
(7107 cases and 7233 controls). Furthermore, we found that several SNPs acted as protective factors according to the overall pooled result in certain genetic models, such as let-7 rs10877887 (T/C; TT vs. TC + $\mathrm{CC}: \mathrm{OR}=0.80,95 \% \mathrm{CI}=0.68-0.95, \mathrm{P}-\mathrm{H}=0.81 ; \mathrm{TT}$ vs. $\mathrm{TC}: \mathrm{OR}=0.77,95 \% \mathrm{CI}=0.64-0.92, \mathrm{P}-\mathrm{H}=0.54$ ), miR-124-1 rs531564(C/G; CC + CG vs. GG: 
$\mathrm{OR}=0.46,95 \% \mathrm{CI}=0.28-0.75, \mathrm{P}-\mathrm{H}=0.31 ; \mathrm{CC}$ vs. $\mathrm{GG}$ : $\mathrm{OR}=0.45,95 \% \mathrm{CI}=0.27,0.75, \mathrm{P}-\mathrm{H}=0.34$ ), and $\mathrm{miR}-$ $608 \mathrm{rs} 4919510(\mathrm{G} / \mathrm{C} ; \mathrm{GG}+\mathrm{GC}$ vs. $\mathrm{CC}: \mathrm{OR}=0.82,95 \%$ $\mathrm{CI}=0.68-0.98, \mathrm{P}-\mathrm{H}=0.07)$, which were supported by two comparisons (1002 cases and 1293 controls), two comparisons (1738 cases and 1961 controls), and four comparisons (3191 cases and 3899 controls), respectively.

Statistical heterogeneity was found in 11 SNPs. Eight SNPs underwent subgroup analysis to detect the source of heterogeneity, while miR-218-2 rs11134527 (G/A), and miR-27a rs895819 (T/C), miR-449b rs10061133 (A/G) were not subjected to subgroup analysis because the number of included studies was too small $(n=2)$. According to the methods described in methods part, subgroup analysis was performed based on ethnicity and cancer type. The results of subgroup analysis were listed in Supplementary Table 5. The forest plots of subgroup analysis of four SNPs, such as mir-26a-1 rs7372209 (C/T), miR-34b/c rs4938723 (T/C), miR-423 rs6505162 (C/A), and miR-608 rs4919510 (G/C), were shown in Figures 2-5.

MiR-146a rs2910164 (G/C) was found to be related to NPC susceptibility $(\mathrm{G}$ allele vs. $\mathrm{C}$ allele: $\mathrm{OR}=1.39,95 \% \mathrm{CI}=1.12-1.72, \mathrm{P}-\mathrm{H}=0.88 ; \mathrm{GG}+\mathrm{GC}$ vs. $\mathrm{CC}$ : $\mathrm{OR}=1.77,95 \% \mathrm{CI}=1.31-2.40, \mathrm{P}-\mathrm{H}=0.92$; $\mathrm{GG}$ vs. $\mathrm{CC}: \mathrm{OR}=1.64,95 \% \mathrm{CI}=1.02-2.61, \mathrm{P}-\mathrm{H}=$ 0.57 ), while only two comparisons (393 cases and 373 controls) were included in this subgroup. We also found that miR-196a2 rs11614913T allele could significantly increase $\mathrm{HNC}$ risk in Asian populations $(\mathrm{CC}+\mathrm{CT}$ vs. TT: $\mathrm{OR}=1.14,95 \% \mathrm{CI}=1.01-1.22, \mathrm{P}-\mathrm{H}=0.04)$ supported by 10 comparisons (5189 cases and 5213 controls). SNP miR-196a2 rs11614913 was also found to be related to OSCC susceptibility by pooled result of four comparisons (1561 cases and 1304 controls). Protective factors were also evaluated in specific ethnic backgrounds or cancer types. SNP miR-608 rs4919510 (G/C) showed protective effect on NPC susceptibility (G allele vs. C allele: $\mathrm{OR}=0.83,95 \% \mathrm{CI}=0.75-0.91, \mathrm{P}-\mathrm{H}=0.8 ; \mathrm{GG}$ vs. $\mathrm{GC}+\mathrm{CC}: \mathrm{OR}=0.81,95 \% \mathrm{CI}=0.70-0.94, \mathrm{P}-\mathrm{H}=0.73$; $\mathrm{GG}+\mathrm{GC}$ vs. $\mathrm{CC}: \mathrm{OR}=0.74,95 \% \mathrm{CI}=0.63-0.86$, $\mathrm{P}-\mathrm{H}=0.92$; GG vs. $\mathrm{CC}: \mathrm{OR}=0.68,95 \% \mathrm{CI}=0.57-0.82$, $\mathrm{P}-\mathrm{H}=0.77$ ), while only two comparisons (1590 cases and 1979 controls) were included in this subgroup. In addition, miR-499a rs3746444 (T/C) was found to be a protective factor in Caucasian populations (CC vs. CT + TT: $\mathrm{OR}=0.80,95 \% \mathrm{CI}=0.69-0.94, \mathrm{P}-\mathrm{H}=0.54)$, and contributed to ESCC (C allele vs. T allele: $\mathrm{OR}=0.80,95 \% \mathrm{CI}=0.66-0.98$, $\mathrm{P}-\mathrm{H}=0.75)$, as supported by the pooled result of two comparisons (669 cases and 688 controls).

Interestingly, the overall pooled result for miR-34b/c rs4938723 (T/C) differed from the subgroup analysis result. The overall pooled result of four comparisons (2739 cases and 3327 controls) indicated that SNP miR-34b/c rs4938723 (T/C) was associated with HNC susceptibility (TT vs. TC: OR $=1.23,95 \% \mathrm{CI}=1.03-1.47$,
$\mathrm{P}-\mathrm{H}=0.06$ ), while subgroup analysis showed its protective effect against ESCC (TT + TC vs. CC: OR $=0.77,95 \%$ $\mathrm{CI}=0.60-0.97, \mathrm{P}-\mathrm{H}=0.38)$, as supported by pooled result of two comparisons (1738 cases and 1961 controls).

In addition, omitting the cohorts whose control group was not in agreement with HWE did not change the result of meta-analysis (data not shown). Besides, omitting the cohorts that were considered as high risk of bias did not changed the results of meta-analyses (data not shown). The influence of cohort that was considered as medium risk of bias on the pooled result would be discussed in conclusion below.

\section{Sensitivity analysis and publication bias}

No significant change was observed when omitting individual studies in turn, suggesting that the results were reliable. Publication bias of the two SNPs, such as miR146a rs2910164 and miR-196a2 rs11614913 was detected by funnel plots (Supplementary Figure 2). Asymmetry of the funnel plots of some genetic models was observed, while no significant publication bias was found by Harbord test (Supplementary Table 3).

\section{DISCUSSION}

Identifying genetic markers of cancer susceptibility and gene-environment interactions could contribute to the reduction of cancer mortality through early diagnosis and personalized therapy [20]. Genome-wide association studies (GWAS) have greatly extended our knowledge of SNPs associated with disease phenotypes, and demonstrated that $88 \%$ of associated SNPs are located in non-coding regions (either intronic or intergenic) $[70,71]$. Since the role of genetic polymorphisms in HNC aetiology has been confirmed, the relationship between SNPs in these non-coding regions and HNC susceptibility has drawn increasing attention from many researchers. However, stronger evidence is needed to validate and further support this relationship. Thus, the purpose of our meta-analysis was to develop a more comprehensive understanding of the changes involved in HNC.

According to a recent study by the ENCODE Project Consortium, approximately 9640 lncRNA gene loci are present in the human genome, while the total number continues to grow [70-73]. The current knowledge related to the interaction between IncRNAs and cancer mainly includes changes in cancer-related lncRNA expression in cancer cells, suggesting that IncRNAs contribute to cancer susceptibility [22]. However, the precise mechanism by which lncRNA polymorphisms are responsible for the oncogenesis remains unknown, since how lncRNA polymorphisms affect the interaction with other biomolecules, such as DNA, protein and other RNA, it is not yet fully understood [22]. 


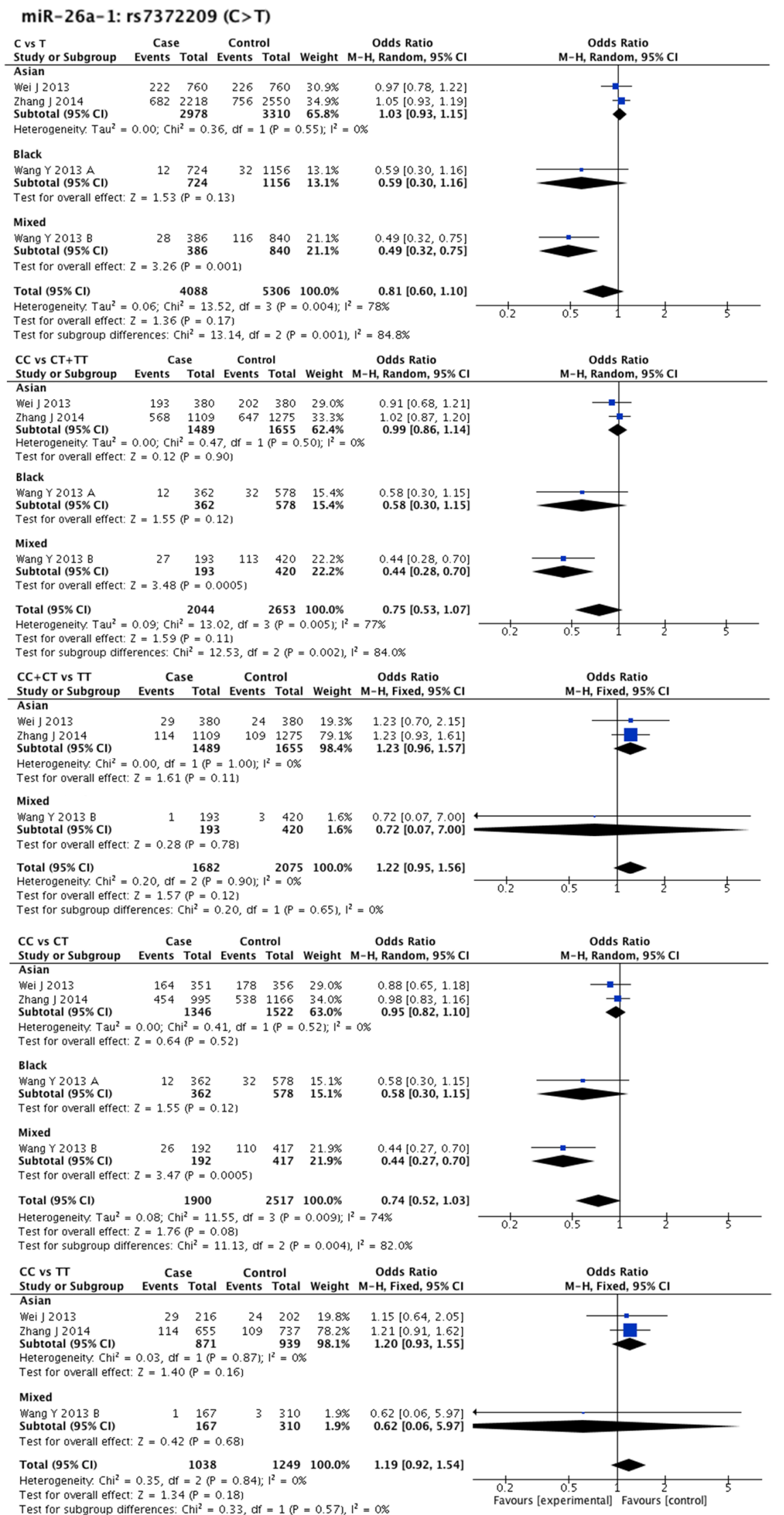

Figure 2: Forest plots of effect estimates for miR-26a-1. Five forest plots of each lncRNA are corresponded to five genetic models. Since all the participants of miR-26a-1 are ESCC, subgroup analysis was only performed based on ethnicity. 


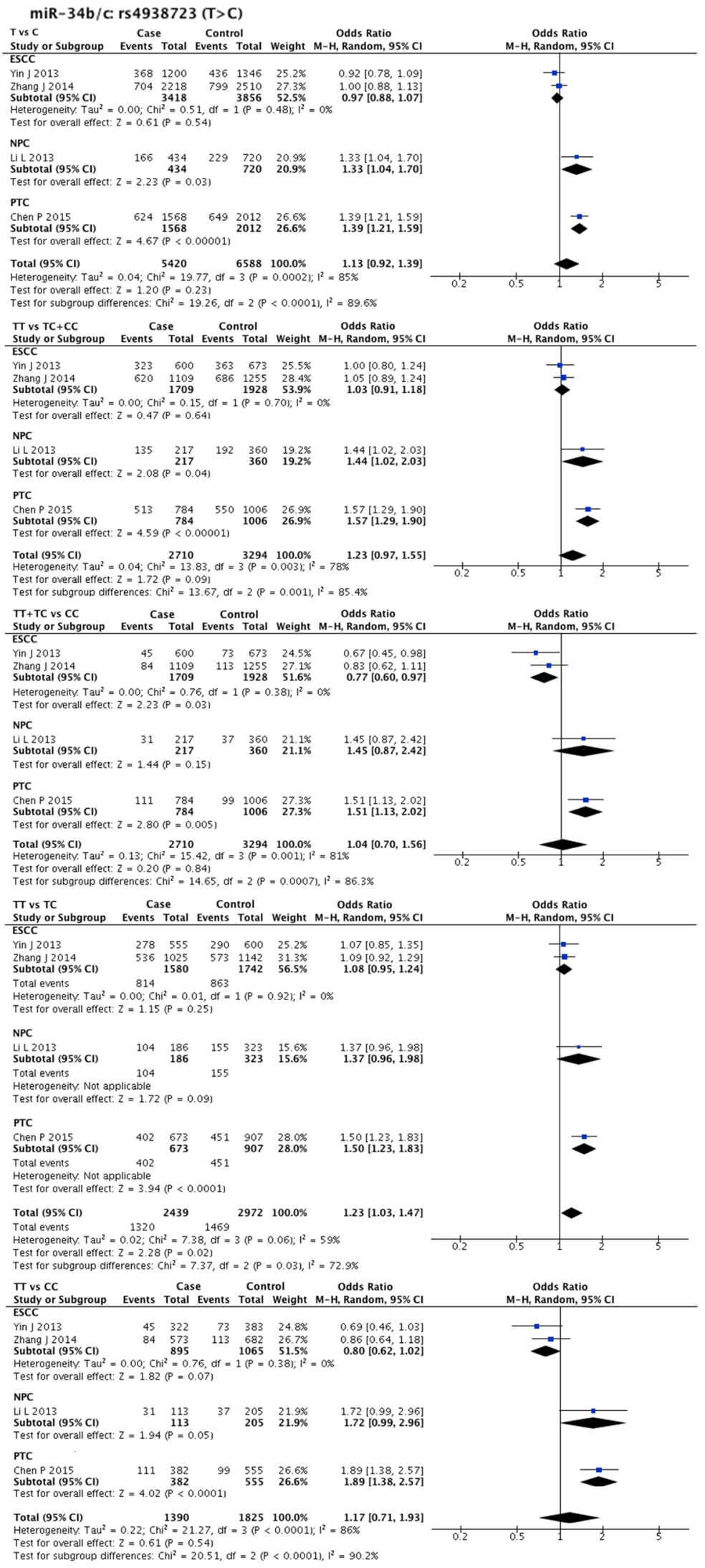

Figure 3: Forest plots of effect estimates for miR-34bc. Five forest plots of each IncRNA are corresponded to five genetic models. Since all the participants of miR-34bc are Asian, subgroup analysis was only performed based on the type of cancer. ESCC: esophageal squamous cell carcinoma; NPC: nasopharyngeal carcinoma; PTC: papillary thyroid carcinoma. 


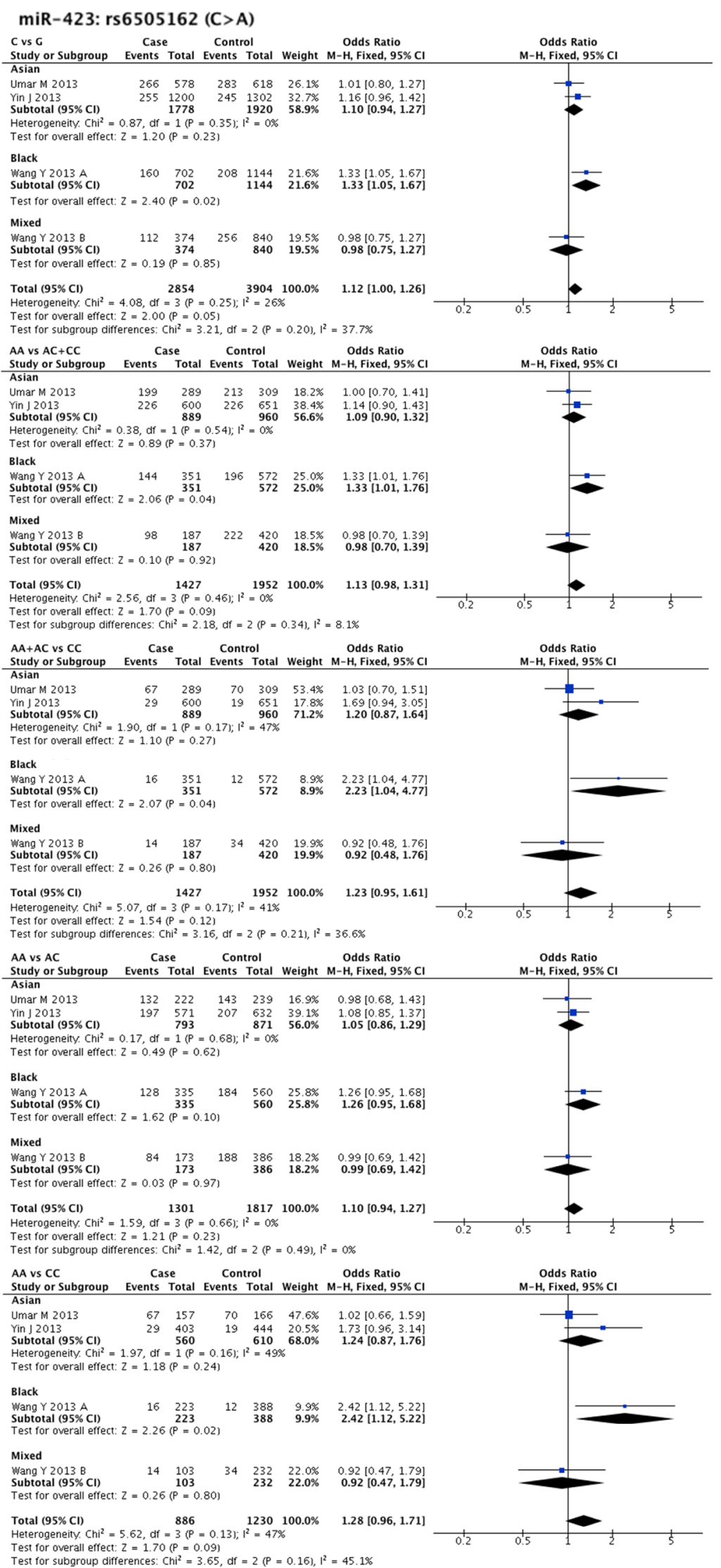

Figure 4: Forest plots of effect estimates for miR-423. Five forest plots of each lncRNA are corresponded to five genetic models. Since all the participants of miR-423 are ESCC, subgroup analysis was only performed based on ethnicity. 


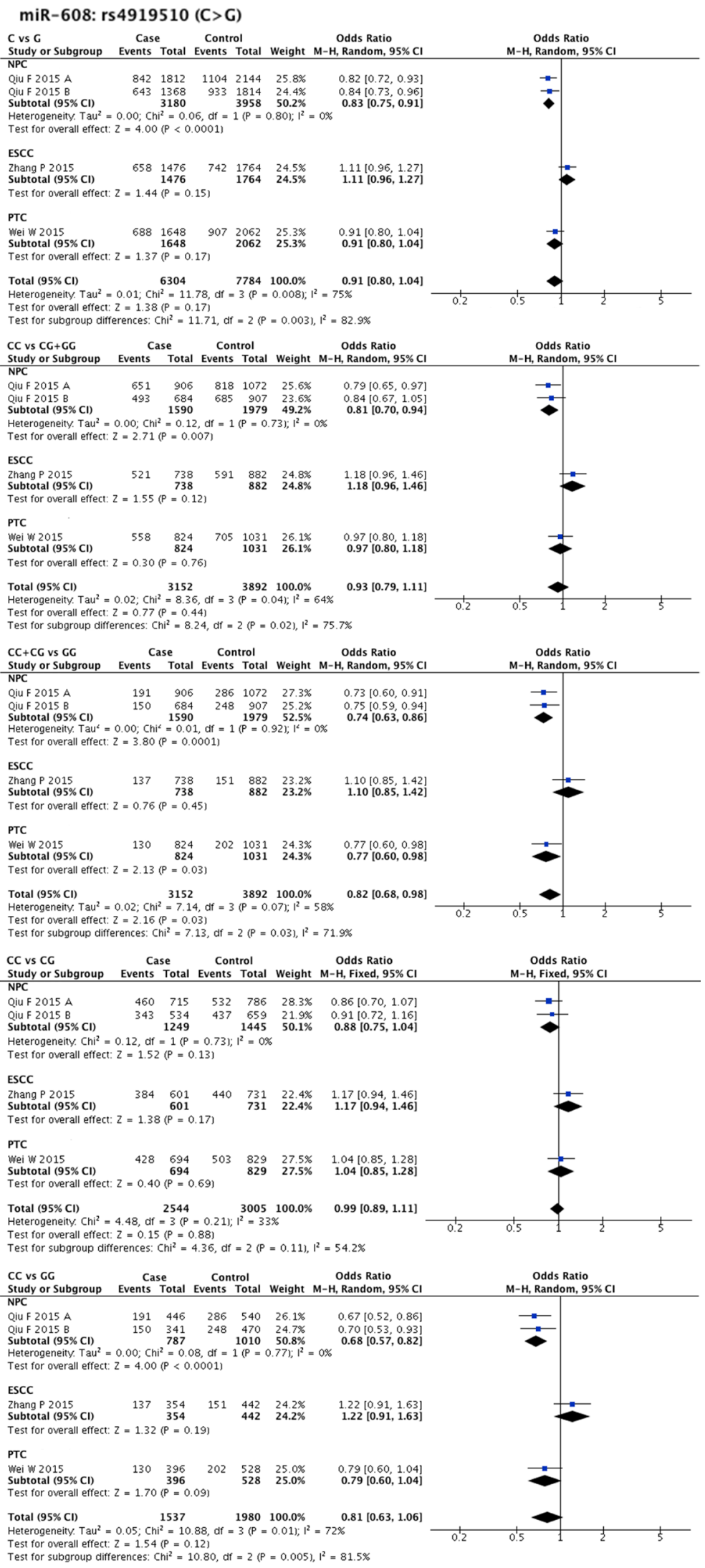

Figure 5: Forest plots of effect estimates for miR-608. Five forest plots of each lncRNA are corresponded to five genetic models. Since all the participants of miR-608 are Asian, subgroup analysis was only performed based on the type of cancer. ESCC: esophageal squamous cell carcinoma; NPC: nasopharyngeal carcinoma; PTC: papillary thyroid carcinoma. 
A large number of studies have proved that HOTAIR can act as an oncogene [74-76]. HOTAIR rs920778T allele is significantly correlated with increased HOTAIR RNA expression [58] which might result in malignant transformation of normal cells [74-76]. Regarding uc003opf.1 rs11752942, a change from A allele to $G$ allele could significantly decrease lncRNA expression and directly suppress tumour development [46]. In accordance with its biological functions, our meta-analysis results demonstrated that HOTAIR rs920778 (C/T) and uc003opf.1 rs11752942 (A/G) could significantly increase and decrease, respectively, ESCC risk in Chinese populations. However, it is noteworthy that 3 comparisons investigating HOTAIR rs920778, as well as 2 comparisons investigating uc003opf.1 rs11752942, were provided by one single study $[46,58]$. Thus, more case-control studies are needed to confirm the relationship between these two SNPs and HNC susceptibility.

Biogenesis and maturation of miRNAs is well depicted by several studies over the past decades [77-83]. Briefly, miRNA gene loci are transcribed by RNA polymerase II in order to synthetize primary miRNAs (primiRNAs) transcripts. Pri-miRNAs are then enzymatically cleaved by DROSHA complex to release small hairpins and form stem-loop precursor miRNAs (pre-miRNAs). After moving from the nucleus to the cytoplasm, pre-miRNAs are subsequently converted by the DICER complex to mature miRNAs. Mature miRNAs usually bind to the $3^{\prime}$ untranslated region (UTR), as well as 5' UTR and coding regions of target mRNAs to mediate translational repression or RNA degradation. On the basis of the above process, SNPs residing in miRNA gene loci may affect one, two or all three steps, such as transcription of the primary transcript, processing of pri-miRNAs and pre-miRNAs, and miRNA-mRNA interactions. The effects above may result in increasing or decreasing of mature miRNAs levels, enhancement or suppression of target gene identification, and even destruction of target binding sites [20]. As miRNAs are functionally associated with oncogenesis and have the ability to simultaneously affect many genes, SNPs in miRNAs could theoretically lead to phenotypic variations that contribute to cancer susceptibility.

Large numbers of systematic reviews have been performed to investigate the association between miRNAs SNPs and cancer susceptibility, including breast cancer, colorectal cancer, gastric cancer, liver cancer, lung cancer [84-90]. In contrast, only few systematic reviews are available on the relationship between HNC susceptibility and miRNAs SNP [2, 91]. Compared to a recently published systematic review [2], a certain number of new studies were added in the meta-analysis of the present systematic review, including 11 new studies investigating mir-146a rs2910164, eight new studies investigating mir-196a rs11614913, six new studies investigating mir-499a rs3746444, and two new studies investigating mir-149 rs2292832. Besides, we also analysed another
15 SNPs residing in miRNA gene loci, which were not included in the meta-analysis by Niu et al. [2]. Hence, to the best of our knowledge, the present systematic review represents the most comprehensive meta-analysis since it incorporated the most recent studies when compared to other reviews associated to miRNA SNPs and HNC susceptibility relationship.

The SNP rs2910164 in miR-146a is located in the stem region of the precursor opposite to the mature miR146 sequence, therefore a change from $\mathrm{G}$ allele to $\mathrm{C}$ allele could affect the stem structure of the miR-146a precursor, thus decreasing mature miRNA expression and suppressing oncogenesis [28, 92]. The miRNA-146a rs2910164 (G/C) polymorphism is the most widely investigated miRNA SNP related to HNC. A total of 20 comparisons from 18 included studies reported the association between this SNP and HNC risk. Unexpectedly, no significant association was found between this SNP and HNC susceptibility in the overall results of our meta-analysis. In contrast to a previous meta-analysis which found that miR-146a rs2910164 gene polymorphism contributed to HNC risk in Asian populations [91], our metaanalysis did not show any correlation when subgroup analyses among ethnic backgrounds were performed. In regards to cancer types, only increased NPC risk associated with this SNP was found in several comparative models (G vs. C, $\mathrm{GG}+\mathrm{GC}$ vs. $\mathrm{CC}$ and GG vs. CC), suggesting that $\mathrm{C}$ allele or $\mathrm{CC}$ genotype represented NPC risk factors. However, the conclusion above needs further confirmation since the sample size of this positive pooled result is small (393 cases and 373 controls).

MiR-196a 2 is composed of two different mature miRNAs, such as miR-196a-5P and miR-196a-3P, both processed from the same stem-loop [93]. Rs11614913 is located in the mature sequence of miR-196a-3P, thus, a change from $\mathrm{C}$ allele to $\mathrm{T}$ allele could lead to less efficient processing of the miRNA precursor to its mature form, as well as diminished capacity to regulate target genes [93]. Our systematic review highlighted a significant association between miR-196a 2 rs11614913 T allele and increased HNC risk in the co-dominant models. Subgroup analysis results demonstrated that this SNP contributed to OSCC susceptibility, as well as total HNC risk in Asian populations. The results above were consistent with the results of a recently published meta-analysis, which also indicated that the miRNA-196a2 rs11614913 (C/T) may play a risk role in the development of HNC [2]. Hence, our meta-analysis confirmed that the detection of miR$196 \mathrm{a} 2$ rs 11614913 polymorphism could be useful in HNC prediction and prevention.

SNPs resident in miRNAs gene loci could not only increase cancer risk, but also play protective roles in cancer development. In the present work, we found four miRNA related SNPs, such as miR-499a rs3746444 (T/C), miR-608 rs4919510 (G/C), let-7 rs10877887 (T/C), and miR-124-1 rs531564 (C/G), significantly associated with decreased $\mathrm{HNC}$ risk after meta-analysis. 
The correlation between SNP rs3746444 in miR499a and HNC susceptibility was broadly investigated, thus a total of 9 studies were included into our metaanalysis. Although the overall pooled results were not statistically significant, subgroup analysis demonstrated that this SNP was associated with decreased HNC risk, as well as ESCC risk, in Caucasian populations. The rs4919510 is located in the miR-608 mature sequence, thus the mutant $\mathrm{C}$-allelic mir-608 exerts a significantly lower colony formation in vitro [64]. In accordance with the functional assay, the overall and subgroup pooled results of the present meta-analysis also indicated that the $\mathrm{G}>\mathrm{C}$ variation of miR-608 rs4919510 was protective against $\mathrm{HNC}$ development.

Let-7 is functionally considered as a tumour suppressor gene due to its role of repressing RAS family [94, 95]. Similarly, miR-124-1 rs531564 GG genotype may promote miR-124 expression, which can directly suppress the expression of its targeting oncogene PTBP1, thus acting as a tumour suppressor [57, 96]. Accordingly, our meta-analysis suggested that the SNPs located in let-7 and miR-124 were both associated with decreased HNC risk.

On the other hand, the overall pooled result demonstrated that miR-34b/c rs4938723 (T/C) was a risk factor for $\mathrm{HNC}$ in the co-dominant model, but showed a protective effect on ESCC development in the recessive model. The reason for this divergence is difficult to understand. On the basis of our results we could only postulate that the same miRNA SNP could exert different effects in different cancer types.

Taken together, our present meta-analysis highlighted that systematic and comprehensive literature searching and inclusion, large sample size inclusion, consistency with HWE in almost all of the included cohorts, and reliable meta-analysis results confirmed by sensitive analysis and subgroup analysis, represent important and adequate elements to create a more comprehensive and reliable framework for understanding the potential roles of ncRNA polymorphisms in determining HNC susceptibility. However, there were still some limitations in this systematic review. Firstly, we included oesophageal cancer despite our intention to analyse HNC risk. Only cancers originating from the cervical oesophagus, which begins at the level of cricopharyngeus muscle and extends down to the sternal notch, could be anatomically considered as a HNC subtype. However, after full text screening, we did not find any study investigating ESCC related ncRNA SNPs related to each anatomical cancer location, such as cervical oesophagus, thoracic oesophagus, and abdominal oesophagus. After discussion, we decided to include these studies with the objective to provide a wider perspective for understanding HNC. Secondly, statistical heterogeneity was significant in some metaanalyses, which might be due to the difference between studies in cancer types and ethnic backgrounds. Thirdly, the present meta-analysis was based on unadjusted OR estimates. Lack of sufficient information made a more precise evaluation with ORs adjusted by other covariates including age, gender, smoking status, viral infections, difficult. Fourthly, since quite a few meta-analyses were performed, multiple comparison problem should be considered carefully. Multiple comparison problem may occur when several statistical interferences were considered simultaneously. In this systematic review, five genetic models were used, it may increase the risk of incorrect rejections of null hypotheses, i.e. false positive or type I error. If only one of the five genetic models showed positive result, such as miR-34b/c rs4938723, miR-196a2 rs11614913 and miR-608 rs4919510, the reliability of the result should be considered. Finally, the methodological quality assessed by NOS of several included studies was considered low, which indicated high risk of bias. Inadequate methodological design frequently occurred in the selection of controls. Controls should be frequencymatched in confounding factors, including age, gender and ethnic backgrounds with cases. Rather than just reporting no difference between case and control, the consistency of baseline should be ahead of the selection of controls, or adjust the OR for the confounding factors. Besides, the response rate of case and control was barely reported, and several studies were hospital-based, which could both lead to an increased risk of selection bias. Despite these limitations, our work revealed that an updated and comprehensive meta-analysis is of utmost importance for obtaining reliable results.

\section{MATERIALS AND METHODS}

The protocol of the present systematic review was approved by the institutional review board. Study selection, data extraction and quality assessment were performed by two authors (Pan $\mathrm{W}$ and $\mathrm{Wu} \mathrm{C}$ ) in duplicate, and discrepancies were resolved through consensus discussion.

\section{Inclusion criteria}

Studies that met the following inclusion criteria were included in the present systematic review: (1) cohort study or case-control study as study design; (2) patients with diagnosed HNC; (3) controls without any cancer history; (4) study that evaluated the association between ncRNAs polymorphisms and HNC susceptibility; and (5) collect an amount of sufficient data to calculate odds ratios (OR) and 95\% confidence intervals (95\% CI). Furthermore, patients risk suffering a secondary primary cancer, which might be the result of field cancerization. Based on this, malignancies located in oral cavity, pharynx, larynx, cervical oesophagus, paranasal sinuses, nasal cavity, salivary glands and thyroid gland, were preferred to be considered together. Thus, in the present 
systematic review, the malignancies mentioned above were regarded as $\mathrm{HNC}$ and included.

\section{Search strategy}

The following electronic databases were employed: MEDLINE (via OVID, 1948 to March 16, 2016), EMBASE (via OVID, 1984 to March 16, 2016), Chinese BioMedical Literature Database (CBM, 1978 to March 16, 2016), and China National Knowledge Infrastructure (CNKI, 1994 to March 16, 2016). The search strategy we used combined Medical Subject Headings (MeSH) with free text words. The MeSH terms used were "RNA, Untranslated", "Polymorphism, Genetic" and "Head and Neck Neoplasms". Relevant journals and reference lists of included studies were manually searched. The titles and abstracts of all studies were initially scanned to find any eligible study. The full text of the potential eligible studies was obtained to confirm their eligibility.

\section{Data extraction and quality assessment}

For each included study, the following information was extracted: 1) first author name and publication year; 2) country of origin; 3) ethnicity, such as Asian, Caucasian and Black; 4) study design; 5) cancer type; 6) cases and controls number; 7) important information regarding the recruiting process; 8) candidate ncRNAs, with the ancestral allele of a certain genetic loci; and 9) genotype distribution of cases and controls. The data of each cohort were extracted separately and the cohorts were considered as different comparisons in further statistical analyses when more than one cohort was reported in one single study, including cohorts from different countries and cohorts from different regions of one country. Furthermore, since the minor allele frequency in control group varied in different ethnicity background, we decided to take the ancestral allele found in the dbSNP database (available at: http://www.ncbi.nlm.nih.gov/projects/SNP) as the original allele, and the variant alleles at the same genetic locus as exposure factor.

NOS (available at: http://www.ohri.ca/programs/ clinical_epidemiology/oxford.asp) was chosen as the tool to assess the methodological quality of included studies. Studies rated 0-3 stars would be considered as high risk of bias, while 4-6 stars 7-9 stars and would be considered as medium and low risk of bias.

\section{Statistical analysis}

Hardy-Weinberg equilibrium (HWE) was used to assess genotype distribution of controls and a goodnessof-fit test (chi-square or Fisher exact test) was performed assess the departure from HWE.

The meta-analysis was performed using RevMan version 5.3 from Cochrane Collaboration, and pooled
ORs with 95\% CIs were calculated separately in different genetic models to evaluate the association between ncRNA polymorphisms and $\mathrm{HNC}$ risk. Using SNP $\mathrm{C}>\mathrm{T}$ as an example, OR and $95 \% \mathrm{CI}$ were calculated in four genetic models, including allele contrast (C vs. T), dominant model ( $\mathrm{CC}$ vs. $\mathrm{CT}+\mathrm{TT})$, recessive model $(\mathrm{CC}+\mathrm{CT}$ vs. TT), and co-dominant model (CC vs. CT, CC vs. TT). The significance of the pooled OR was determined by the 2 -tailed $\mathrm{z}$-test and $P<0.05$ was considered statistically significant. Subgroup analysis was also performed based on ethnicity background and cancer type.

Statistical heterogeneity between studies was analysed by Cochran's Q statistic following a chi-square distribution and $\mathrm{I}^{2}$ statistics. When $P>0.05$ and $\mathrm{I}^{2}<50 \%$, a fixed-effects model was applied; when $p \leq 0.05$ or $\mathrm{I}^{2}$ $\geq 50 \%$, a random-effects model was applied. To ensure the reliability of the results, sensitivity analysis was performed by omitting each study in turn. Publication bias was detected by the funnel plot when the number of included studies was more than 10 , since limited number of included studies would affect the power of the tests to distinguish chance from real asymmetry. Harbord test was chosen as test for funnel plot asymmetry. The trim and fill method was applied to identify and correct for funnel plot asymmetry arising from publication bias. Sensitive analysis and detection of publication bias were conducted with STATA Version 14.0 software (Stata Corp, College Station, TX, USA).

\section{Abbreviations}

SNP: single nucleotide polymorphisms; ncRNA: non-coding RNAs; HNC: head and neck cancer; miRNAs: micro RNAs; lncRNAs: long non-coding RNAs; HNSCC: head and neck squamous cell carcinoma; NPC: nasopharyngeal carcinoma; OSCC: oral squamous cell carcinoma; ESCC: oesophageal squamous cell carcinoma; PTC: papillary thyroid carcinoma; LSCC: laryngeal squamous cell carcinoma; TC: thyroid carcinoma; GWAS: Genome-wide association studies; pri-miRNAs: primary miRNAs; pre-miRNAs: precursor miRNAs; UTR: untranslated region; OR: odds ratios; 95\% CI: 95\% confidence intervals; MeSH: Medical Subject Headings; HWE: Hardy-Weinberg equilibrium; NOS: NewcastleOttawa quality assessment scale.

\section{Author contributions}

Both Pan $\mathrm{W}$ and $\mathrm{Wu} \mathrm{C}$ contributed equally in this manuscript. Pan $\mathrm{W}$ and $\mathrm{Wu} \mathrm{C}$ wrote the manuscript and prepared Table 1 and Supplementary Tables 4-5 and Supplementary Tables $1-2$. Su Z and Duan Z prepared Figures 1-5. Li L, Mi F and Li C supervised the organization of the manuscript. All authors reviewed the manuscript. 


\section{CONFLICTS OF INTEREST}

There were no conflicts of interest.

\section{FUNDING}

This systematic review was supported by National Natural Science Foundation of China (Grant No.81500807) and Outstanding Youth Foundation of Sichuan University (2082604194311). The funder had no role in study design, data collection and analysis, decision to publish or preparation of the manuscript.

\section{REFERENCES}

1. Mehanna H, Paleri V, West CM, Nutting C. Head and neck cancer-Part 1: Epidemiology, presentation, and prevention. BMJ. 2010; 341:c4684.

2. Niu YM, Du XY, Lu MY, Xu QL, Luo J, Shen M. Significant association between functional microRNA polymorphisms and head and neck cancer susceptibility: a comprehensive meta-analysis. Sci Rep. 2015; 5:12972.

3. Argiris A, Karamouzis MV, Raben D, Ferris RL. Head and neck cancer. Lancet. 2008; 371:1695-1709.

4. Ferlay J, Shin HR, Bray F, Forman D, Mathers C, Parkin DM. Estimates of worldwide burden of cancer in 2008: GLOBOCAN 2008. Int J Cancer. 2010; 127:2893-2917.

5. Mehanna H, Jones TM, Gregoire V, Ang KK. Oropharyngeal carcinoma related to human papillomavirus. BMJ. 2010; 340:c1439.

6. Conway DI, Hashibe M, Boffetta P, Wunsch-Filho V, Muscat J, La Vecchia C, Winn DM. Enhancing epidemiologic research on head and neck cancer: INHANCE - The international head and neck cancer epidemiology consortium. Oral oncology. 2009; 45:743-746.

7. Hashibe M, Brennan P, Benhamou S, Castellsague X, Chen C, Curado MP, Dal Maso L, Daudt AW, Fabianova E, Fernandez L, Wunsch-Filho V, Franceschi S, Hayes RB, et al. Alcohol drinking in never users of tobacco, cigarette smoking in never drinkers, and the risk of head and neck cancer: pooled analysis in the International Head and Neck Cancer Epidemiology Consortium. J Natl Cancer Inst. 2007; 99:777-789.

8. Carninci P, Kasukawa T, Katayama S, Gough J, Frith MC, Maeda N, Oyama R, Ravasi T, Lenhard B, Wells C, Kodzius R, Shimokawa K, Bajic VB, et al. The transcriptional landscape of the mammalian genome. Science. 2005; 309:1559-1563.

9. Djebali S, Davis CA, Merkel A, Dobin A, Lassmann T, Mortazavi A, Tanzer A, Lagarde J, Lin W, Schlesinger F, Xue C, Marinov GK, Khatun J, et al. Landscape of transcription in human cells. Nature. 2012; 489:101-108.

10. Consortium EP, Birney E, Stamatoyannopoulos JA, Dutta A, Guigo R, Gingeras TR, Margulies EH, Weng Z, Snyder M,
Dermitzakis ET, Thurman RE, Kuehn MS, Taylor CM, et al. Identification and analysis of functional elements in $1 \%$ of the human genome by the ENCODE pilot project. Nature. 2007; 447:799-816.

11. Colombo T, Farina L, Macino G, Paci P. PVT1: a rising star among oncogenic long noncoding RNAs. BioMed research international. 2015; 2015:304208.

12. Pauli A, Rinn JL, Schier AF. Non-coding RNAs as regulators of embryogenesis. Nature reviews Genetics. 2011; 12:136-149.

13. Kong YW, Ferland-McCollough D, Jackson TJ, Bushell M. microRNAs in cancer management. Lancet Oncol. 2012; 13:e249-258.

14. Zhang B, Pan X, Cobb GP, Anderson TA. microRNAs as oncogenes and tumor suppressors. Developmental biology. 2007; 302:1-12.

15. Guttman M, Rinn JL. Modular regulatory principles of large non-coding RNAs. Nature. 2012; 482:339-346.

16. Ulitsky I, Bartel DP. lincRNAs: genomics, evolution, and mechanisms. Cell. 2013; 154:26-46.

17. Prensner JR, Chinnaiyan AM. The emergence of lncRNAs in cancer biology. Cancer Discov. 2011; 1:391-407.

18. Wang J, Shao N, Ding X, Tan B, Song Q, Wang N, Jia Y, Ling H, Cheng Y. Crosstalk between transforming growth factor-beta signaling pathway and long non-coding RNAs in cancer. Cancer letters. 2016; 370:296-301.

19. International HapMap Consortium, Frazer KA, Ballinger DG, Cox DR, Hinds DA, Stuve LL, Gibbs RA, Belmont JW, Boudreau A, Hardenbol P, Leal SM, Pasternak $\mathrm{S}$, Wheeler DA, et al. A second generation human haplotype map of over 3.1 million SNPs. Nature. 2007; 449:851-861.

20. Ryan BM, Robles AI, Harris CC. Genetic variation in microRNA networks: the implications for cancer research. Nat Rev Cancer. 2010; 10:389-402.

21. International HapMap Consortium. A haplotype map of the human genome. Nature. 2005; 437:1299-1320.

22. Wapinski O, Chang HY. Long noncoding RNAs and human disease. Trends Cell Biol. 2011; 21:354-361.

23. Abelson JF, Kwan KY, O'Roak BJ, Baek DY, Stillman AA, Morgan TM, Mathews CA, Pauls DL, Rasin MR, Gunel M, Davis NR, Ercan-Sencicek AG, Guez DH, et al. Sequence variants in SLITRK1 are associated with Tourette's syndrome. Science. 2005; 310:317-320.

24. Akkiz H, Bayram S, Bekar A, Akgollu E, Uskudar O, Sandikci M. No association of pre-microRNA-146a rs2910164 polymorphism and risk of hepatocellular carcinoma development in Turkish population: a casecontrol study. Gene. 2011; 486:104-109.

25. Wang PY, Gao ZH, Jiang ZH, Li XX, Jiang BF, Xie SY. The associations of single nucleotide polymorphisms in miR-146a, miR-196a and miR-499 with breast cancer susceptibility. PLoS One. 2013; 8:e70656.

26. Du W, Ma XL, Zhao C, Liu T, Du YL, Kong WQ, Wei BL, Yu JY, Li YY, Huang JW, Li ZK, Liu L. Associations of 
single nucleotide polymorphisms in miR-146a, miR-196a, miR-149 and miR-499 with colorectal cancer susceptibility. Asian Pac J Cancer Prev. 2014; 15:1047-1055.

27. Hasani SS, Hashemi M, Eskandari-Nasab E, Naderi M, Omrani M, Sheybani-Nasab M. A functional polymorphism in the miR-146a gene is associated with the risk of childhood acute lymphoblastic leukemia: a preliminary report. Tumour Biol. 2014; 35:219-225.

28. Jazdzewski K, Murray EL, Franssila K, Jarzab B, Schoenberg DR, de la Chapelle A. Common SNP in premiR-146a decreases mature miR expression and predisposes to papillary thyroid carcinoma. Proc Natl Acad Sci USA. 2008; 105:7269-7274.

29. Christensen BC, Avissar-Whiting M, Ouellet LG, Butler RA, Nelson HH, McClean MD, Marsit CJ, Kelsey KT. Mature MicroRNA Sequence Polymorphism in MIR196A2 Is Associated with Risk and Prognosis of Head and Neck Cancer. Clin Cancer Res. 2010; 16:3713-3720.

30. Guo H, Wang K, Xiong G, Hu HM, Wang DM, Xu XQ, Guan XY, Yang K, Bai Y. A functional varient in microRNA-146a is associated with risk of esophageal squamous cell carcinoma in Chinese Han. Fam Cancer. 2010; 9:599-603.

31. Liu Z, Li G, Wei S, Niu J, El-Naggar AK, Sturgis EM, Wei Q. Genetic variants in selected pre-microRNA genes and the risk of squamous cell carcinoma of the head and neck. Cancer. 2010; 116:4753-4760.

32. Wang K, Guo H, Hu H, Xiong G, Guan X, Li J, Xu X, Yang K, Bai Y. A functional variation in pre-microRNA$196 \mathrm{a}$ is associated with susceptibility of esophageal squamous cell carcinoma risk in Chinese Han. Biomarkers. 2010; 15:614-618.

33. Chu YH, Tzeng SL, Lin CW, Chien MH, Chen MK, Yang SF. Impacts of microRNA gene polymorphisms on the susceptibility of environmental factors leading to carcinogenesis in oral cancer. PLoS One. 2012; 7:e39777.

34. Jones AM, Howarth KM, Martin L, Gorman M, Mihai R, Moss L, Auton A, Lemon C, Mehanna H, Mohan H, Clarke SE, Wadsley J, Macias E, et al. Thyroid cancer susceptibility polymorphisms: confirmation of loci on chromosomes $9 q 22$ and $14 q 13$, validation of a recessive $8 \mathrm{q} 24$ locus and failure to replicate a locus on 5q24. J Med Genet. 2012; 49:158-163.

35. Tu HF, Liu CJ, Chang CL, Wang PW, Kao SY, Yang CC, $\mathrm{Yu}$ EH, Lin SC, Chang KW. The association between genetic polymorphism and the processing efficiency of miR-149 affects the prognosis of patients with head and neck squamous cell carcinoma. PLoS One. 2012; 7:e51606.

36. Li L, Wu J, Sima X, Bai P, Deng W, Deng X, Zhang L, Gao L. Interactions of miR-34b/c and TP-53 polymorphisms on the risk of nasopharyngeal carcinoma. Tumour Biol. 2013; 34:1919-1923.

37. Liu CJ, Tsai MM, Tu HF, Lui MT, Cheng HW, Lin SC. miR196a overexpression and miR-196a2 gene polymorphism are prognostic predictors of oral carcinomas. Ann Surg Oncol. 2013; 20:S406-414.
38. Lung RW, Wang X, Tong JH, Chau SL, Lau KM, Cheng SH, Woo JK, Woo J, Leung PC, Ng MH, Tang NL, To KF. A single nucleotide polymorphism in microRNA-146a is associated with the risk for nasopharyngeal carcinoma. Molecular carcinogenesis. 2013; 52:E28-38.

39. Marino M, Cirello V, Gnarini V, Colombo C, Pignatti E, Casarini L, Diazzi C, Rochira V, Cioni K, Madeo B, Carani C, Simoni M, Fugazzola L. Are pre-miR-146a and PTTG1 associated with papillary thyroid cancer? Endocr Connect. 2013; 2:178-185.

40. Orsos Z, Szanyi I, Csejtei A, Gerlinger I, Ember I, Kiss I. Association of pre-miR-146a rs2910164 polymorphism with the risk of head and neck cancer. Anticancer Res. 2013; 33:341-346.

41. Song X, Sturgis EM, Liu J, Jin L, Wang Z, Zhang C, Wei Q, Li G. MicroRNA variants increase the risk of HPVassociated squamous cell carcinoma of the oropharynx in never smokers. PLoS One. 2013; 8:e56622.

42. Umar M, Upadhyay R, Prakash G, Kumar S, Ghoshal UC, Mittal B. Evaluation of common genetic variants in premicroRNA in susceptibility and prognosis of esophageal cancer. Molecular carcinogenesis. 2013; 52:E10-18.

43. Wang Y, Vogelsang M, Schafer G, Matejcic M, Parker MI. MicroRNA polymorphisms and environmental smoke exposure as risk factors for oesophageal squamous cell carcinoma. PLoS One. 2013; 8:e78520.

44. Wei J, Zheng L, Liu S, Yin J, Wang L, Wang X, Shi Y, Shao A, Tang W, Ding G, Liu C, Chen S, Gu H. MiR-196a2 rs11614913 $\mathrm{T}>\mathrm{C}$ polymorphism and risk of esophageal cancer in a Chinese population. Hum Immunol. 2013; 74:1199-1205.

45. Wei WJ, Wang YL, Li DS, Wang Y, Wang XF, Zhu YX, Yang YJ, Wang ZY, Ma YY, Wu Y, Jin L, Ji QH, Wang JC. Association between the rs2910164 polymorphism in preMir-146a sequence and thyroid carcinogenesis. PLoS One. 2013; 8:e56638.

46. Wu H, Zheng J, Deng J, Hu M, You Y, Li N, Li W, Lu J, Zhou Y. A genetic polymorphism in lincRNA-uc003opf.1 is associated with susceptibility to esophageal squamous cell carcinoma in Chinese populations. Carcinogenesis. 2013; 34:2908-2917.

47. Yin J, Wang X, Zheng L, Shi Y, Wang L, Shao A, Tang W, Ding G, Liu C, Liu R, Chen S, Gu H. Hsa-miR-34b/c rs4938723 $\mathrm{T}>\mathrm{C}$ and hsa-miR-423 rs6505162 $\mathrm{C}>\mathrm{A}$ polymorphisms are associated with the risk of esophageal cancer in a Chinese population. PLoS One. 2013; 8:e80570.

48. Huang GL, Chen ML, Li YZ, Lu Y, Pu XX, He YX, Tang SY, Che H, Zou Y, Ding C, He Z. Association of miR-146a gene polymorphism with risk of nasopharyngeal carcinoma in the central-southern Chinese population. J Hum Genet. 2014; 59:141-144.

49. Jiang L, Wang C, Sun C, Xu Y, Ding Z, Zhang X, Huang J, Yu H. The impact of pri-miR-218 rs11134527 on the risk and prognosis of patients with esophageal squamous cell carcinoma. Int J Clin Exp Pathol. 2014; 7:6206-6212. 
50. Li P, Yan H, Zhang H, Yu L, Wang Z, Zhai Y, Xia X, Zhang J, Zhang Y, Ma F, Huang W, Cai M, Cui Y, et al. A functional polymorphism in MIR196A2 is associated with risk and progression of nasopharyngeal carcinoma in the Chinese population. Genetic testing and molecular biomarkers. 2014; 18:149-155.

51. Lin D, Dong W, Lu M, Xing G, Dong J, Zhang W. The asociation betwen rs2910164 $\mathrm{G}>\mathrm{C}$ polymorphism in pre-microRNA-146a and laryngeal cancer in Jiangsu Han population. J Otolaryngol Ophthal Shandong Univ. 2014; 28:46-50.

52. Palmieri A, Carinci F, Martinelli M, Pezzetti F, Girardi A, Cura F, Rubini C, Scapoli L. Role of the MIR146A polymorphism in the origin and progression of oral squamous cell carcinoma. Eur J Oral Sci. 2014; 122:198-201.

53. Qu Y, Qu H, Luo M, Wang P, Song C, Wang K, Zhang J, Dai L. MicroRNAs related polymorphisms and genetic susceptibility to esophageal squamous cell carcinoma. Mol Genet Genomics. 2014; 289:1123-1130.

54. Roy R, De Sarkar N, Ghose S, Paul RR, Pal M, Bhattacharya C, Chowdhury SK, Ghosh S, Roy B. Genetic variations at microRNA and processing genes and risk of oral cancer. Tumour Biol. 2014; 35:3409-3414.

55. Wang N, Li Y, Zhou RM, Wang GY, Wang CM, Chen ZF, Liu W. Hsa-miR-196a2 functional SNP is associated with the risk of ESCC in individuals under 60 years old. Biomarkers. 2014; 19:43-48.

56. Wei WJ, Lu ZW, Li DS, Wang Y, Zhu YX, Wang ZY, Wu Y, Wang YL, Ji QH. Association of the miR-149 Rs2292832 polymorphism with papillary thyroid cancer risk and clinicopathologic characteristics in a Chinese population. Int J Mol Sci. 2014; 15:20968-20981.

57. Zhang J, Huang X, Xiao J, Yang Y, Zhou Y, Wang X, Liu Q, Yang J, Wang M, Qiu L, Zheng Y, Zhang P, Li J, et al. Pri-miR-124 rs531564 and pri-miR-34b/c rs4938723 polymorphisms are associated with decreased risk of esophageal squamous cell carcinoma in Chinese populations. PLoS One. 2014; 9:e100055.

58. Zhang X, Zhou L, Fu G, Sun F, Shi J, Wei J, Lu C, Zhou C, Yuan Q, Yang M. The identification of an ESCC susceptibility SNP rs920778 that regulates the expression of lncRNA HOTAIR via a novel intronic enhancer. Carcinogenesis. 2014; 35:2062-2067.

59. Zhang Y, Zhu L, Wang R, Miao L, Jiang H, Yuan H, Ma H, Chen N. Genetic variants in let-7/Lin28 modulate the risk of oral cavity cancer in a Chinese Han population. Sci Rep. 2014; 4:7434.

60. Buas MF, Onstad L, Levine DM, Risch HA, Chow WH, Liu G, Fitzgerald RC, Bernstein L, Ye W, Bird NC, Romero Y, Casson AG, Corley DA, et al. MiRNARelated SNPs and Risk of Esophageal Adenocarcinoma and Barrett's Esophagus: Post Genome-Wide Association Analysis in the BEACON Consortium. PLoS One. 2015; 10:e0128617.
61. Chen P, Sun R, Pu Y, Bai P, Yuan F, Liang Y, Zhou B, Wang Y, Sun Y, Zhu J, Zhang L, Gao L. Pri-Mir-34b/C and Tp-53 Polymorphisms are Associated With The Susceptibility of Papillary Thyroid Carcinoma: A CaseControl Study. Medicine (Baltimore). 2015; 94:e1536.

62. Hou YY, Lee JH, Chen HC, Yang CM, Huang SJ, Liou HH, Chi CC, Tsai KW, Ger LP. The association between miR499a polymorphism and oral squamous cell carcinoma progression. Oral diseases. 2015; 21:195-206.

63. Kang M, Sang Y, Gu H, Zheng L, Wang L, Liu C, Shi Y, Shao A, Ding G, Chen S, Tang W, Yin J. Long noncoding RNAs POLR2E rs3787016 $\mathrm{C} / \mathrm{T}$ and HULC rs7763881 $\mathrm{A} / \mathrm{C}$ polymorphisms are associated with decreased risk of esophageal cancer. Tumour Biol. 2015; 36:6401-6408.

64. Qiu F, Yang L, Zhang L, Yang X, Yang R, Fang W, Wu D, Chen J, Xie C, Huang D, Zhou Y, Lu J. Polymorphism in mature microRNA-608 sequence is associated with an increased risk of nasopharyngeal carcinoma. Gene. 2015; 565:180-186.

65. Song X, You W, Zhu J, Cui X, Hu J, Chen Y, Liu W, Wang L, Li S, Wei Y, Yang L, Li F. A Genetic Variant in miRNA-219-1 Is Associated with Risk of Esophageal Squamous Cell Carcinoma in Chinese Kazakhs. Disease markers. 2015; 2015:541531.

66. Wang Y, Wei T, Xiong J, Chen P, Wang X, Zhang L, Gao L, Zhu J. Association Between Genetic Polymorphisms in the Promoter Regions of Let-7 and Risk of Papillary Thyroid Carcinoma: A Case-Control Study. Medicine (Baltimore). 2015; 94:e1879.

67. Wei WJ, Wang YL, Li DS, Wang Y, Wang XF, Zhu YX, Pan XD, Wang ZY, Wu Y, Jin L, Wang JC, Ji QH. Association study of single nucleotide polymorphisms in mature microRNAs and the risk of thyroid tumor in a Chinese population. Endocrine. 2015; 49:436-444.

68. Zhang P, Wang J, Lu T, Wang X, Zheng Y, Guo S, Yang Y, Wang M, Kolluri VK, Qiu L, Shen F, Fan L, Li J, et al. miR-449b rs10061133 and miR-4293 rs12220909 polymorphisms are associated with decreased esophageal squamous cell carcinoma in a Chinese population. Tumour Biol. 2015; 36:8789-8795.

69. Zhang X, Gu Y, Liu X, Yu Y, Shi J, Yu Q, Sun H, Kanu JS, Zhan S, Liu Y. Association of Pre-miR-146a rs2910164 Polymorphism with Papillary Thyroid Cancer. Int J Endocrinol. 2015; 2015:802562.

70. Yang G, Lu X, Yuan L. LncRNA: a link between RNA and cancer. Biochim Biophys Acta. 2014; 1839:1097-1109.

71. Hindorff LA, Sethupathy P, Junkins HA, Ramos EM, Mehta JP, Collins FS, Manolio TA. Potential etiologic and functional implications of genome-wide association loci for human diseases and traits. Proc Natl Acad Sci USA. 2009; 106:9362-9367.

72. ENCODE Project Consortium. An integrated encyclopedia of DNA elements in the human genome. Nature. 2012; 489:57-74. 
73. Derrien T, Johnson R, Bussotti G, Tanzer A, Djebali S, Tilgner H, Guernec G, Martin D, Merkel A, Knowles DG, Lagarde J, Veeravalli L, Ruan X, et al. The GENCODE v7 catalog of human long noncoding RNAs: analysis of their gene structure, evolution, and expression. Genome research. 2012; 22:1775-1789.

74. Niinuma T, Suzuki H, Nojima M, Nosho K, Yamamoto H, Takamaru H, Yamamoto E, Maruyama R, Nobuoka T, Miyazaki Y, Nishida T, Bamba T, Kanda T, et al. Upregulation of miR-196a and HOTAIR drive malignant character in gastrointestinal stromal tumors. Cancer research. 2012; 72:1126-1136.

75. Kogo R, Shimamura T, Mimori K, Kawahara K, Imoto S, Sudo T, Tanaka F, Shibata K, Suzuki A, Komune S, Miyano S, Mori M. Long noncoding RNA HOTAIR regulates polycomb-dependent chromatin modification and is associated with poor prognosis in colorectal cancers. Cancer research. 2011; 71:6320-6326.

76. Gupta RA, Shah N, Wang KC, Kim J, Horlings HM, Wong DJ, Tsai MC, Hung T, Argani P, Rinn JL, Wang Y, Brzoska P, Kong B, et al. Long non-coding RNA HOTAIR reprograms chromatin state to promote cancer metastasis. Nature. 2010; 464:1071-1076.

77. Bagga S, Bracht J, Hunter S, Massirer K, Holtz J, Eachus R, Pasquinelli AE. Regulation by let-7 and lin-4 miRNAs results in target mRNA degradation. Cell. 2005; 122:553-563.

78. Pillai RS, Bhattacharyya SN, Artus CG, Zoller T, Cougot N, Basyuk E, Bertrand E, Filipowicz W. Inhibition of translational initiation by Let-7 MicroRNA in human cells. Science. 2005; 309:1573-1576.

79. Giraldez AJ, Mishima Y, Rihel J, Grocock RJ, Van Dongen S, Inoue K, Enright AJ, Schier AF. Zebrafish MiR430 promotes deadenylation and clearance of maternal mRNAs. Science. 2006; 312:75-79.

80. Orom UA, Nielsen FC, Lund AH. MicroRNA-10a binds the 5'UTR of ribosomal protein mRNAs and enhances their translation. Molecular cell. 2008; 30:460-471.

81. Gu S, Jin L, Zhang F, Sarnow P, Kay MA. Biological basis for restriction of microRNA targets to the 3' untranslated region in mammalian mRNAs. Nat Struct Mol Biol. 2009; 16:144-150.

82. Rigoutsos I. New tricks for animal microRNAS: targeting of amino acid coding regions at conserved and nonconserved sites. Cancer research. 2009; 69:3245-3248.

83. Melo SA, Esteller M. Dysregulation of microRNAs in cancer: playing with fire. FEBS Lett. 2011; 585:2087-2099.

84. Wang B, Ma N, Wang Y. Association between the hsa-mir27 a variant and breast cancer risk: a meta-analysis. Asian Pac J Cancer Prev. 2012; 13:6207-6210.
85. Fan $\mathrm{X}, \mathrm{Wu} \mathrm{Z}$. Effects of four single nucleotide polymorphisms in microRNA-coding genes on lung cancer risk. Tumour Biol. 2014; 35:10815-10824.

86. Peng Q, Li S, Lao X, Chen Z, Li R, Deng Y, Qin X. The association of common functional polymorphisms in mir146a and mir-196a2 and hepatocellular carcinoma risk: evidence from a meta-analysis. Medicine (Baltimore). 2014; 93:e252.

87. Dai ZJ, Shao YP, Wang XJ, Xu D, Kang HF, Ren HT, Min WL, Lin S, Wang M, Song ZJ. Five common functional polymorphisms in microRNAs (rs2910164, rs2292832, rs11614913, rs3746444, rs895819) and the susceptibility to breast cancer: evidence from 8361 cancer cases and 8504 controls. Curr Pharm Des. 2015; 21:1455-1463.

88. Liu XX, Wang M, Xu D, Yang JH, Kang HF, Wang XJ, Lin S, Yang PT, Liu XH, Dai ZJ. Quantitative Assessment of the Association between Genetic Variants in MicroRNAs and Colorectal Cancer Risk. BioMed research international. 2015; 2015:276410.

89. Xu L, Tang W. The associations of nucleotide polymorphisms in mir-196a2, mir-146a, mir-149 with lung cancer risk. Cancer Biomark. 2015; 15:57-63.

90. Xu Q, Liu JW, Yuan Y. Comprehensive assessment of the association between miRNA polymorphisms and gastric cancer risk. Mutat Res Rev Mutat Res. 2015; 763:148-160.

91. Chen XJ, Zhou TY, Chen M, Li N, Liu F. Association of the miRNA146a rs2910164 C > G Polymorphism with Head and Neck Cancer Risk: A Meta-analysis. Asian Pac J Cancer Prev. 2015; 16:3871-3874.

92. Forloni M, Dogra SK, Dong Y, Conte D Jr, Ou J, Zhu LJ, Deng A, Mahalingam M, Green MR, Wajapeyee N. miR146a promotes the initiation and progression of melanoma by activating Notch signaling. Elife. 2014; 3:e01460.

93. Chen C, Zhang Y, Zhang L, Weakley SM, Yao Q. MicroRNA-196: critical roles and clinical applications in development and cancer. J Cell Mol Med. 2011; 15:14-23.

94. Johnson SM, Grosshans H, Shingara J, Byrom M, Jarvis R, Cheng A, Labourier E, Reinert KL, Brown D, Slack FJ. RAS is regulated by the let-7 microRNA family. Cell. 2005; 120:635-647.

95. Kumar MS, Erkeland SJ, Pester RE, Chen CY, Ebert MS, Sharp PA, Jacks T. Suppression of non-small cell lung tumor development by the let-7 microRNA family. Proc Natl Acad Sci USA. 2008; 105:3903-3908.

96. Makeyev EV, Zhang J, Carrasco MA, Maniatis T. The MicroRNA miR-124 promotes neuronal differentiation by triggering brain-specific alternative pre-mRNA splicing. Molecular cell. 2007; 27:435-448. 